\title{
Intensi Berhenti Merokok pada Wanita Emerging Adult Ditinjau dari Prediktor Theory of Planned Behavior
}

\author{
VANIA ARDELIA* \& TRIANA KESUMA DEWI
}

Departemen Psikologi Klinis dan Kesehatan Mental, Fakultas Psikologi Universitas Airlangga

\begin{abstract}
ABSTRAK
Penelitian ini bertujuan untuk mengetahui apakah sikap dan norma subjektif dapat memprediksi intensi berhenti merokok wanita emerging adult. Masa emerging adult merupakan tahap perkembangan dimana prevalensi penyalahgunaan berbagai macam zat paling tinggi ditemukan. Hipotesis dari penelitian ini adalah sikap dan norma subjektif dapat memprediksi intensi berhenti merokok pada wanita emerging adult. Penelitian ini dilakukan pada 211 orang wanita emerging adult, yaitu mereka yang berusia 18-25 tahun. Partisipan mengisi kuesioner yang disusun oleh peneliti menggunakan pendekatan Theory of Planned Behavior dan teori intensi perilaku. Data dianalisis dengan teknik regresi berganda. Hasil penelitian menunjukkan bahwa sikap ( $B=0.229, S E=0.07$, nilai $p=.003)$ dan norma subjektif $(B=0.645$, $S E=.078$, nilai $p=.000$ ) berkorelasi positif dengan intensi berhenti merokok pada wanita emerging adult $\left(F(211)=33.36, d f=207, R^{2}=.325\right.$, nilai $\left.p=.000\right)$. Dari temuan penelitian, dapat disimpulkan bahwa varians skor prediktor berkontribusi sebesar $32.5 \%$ terhadap varians skor variabel dependen.
\end{abstract}

Kata kunci: intensi berhenti merokok, theory of planned behavior, wanita emerging adult

\begin{abstract}
The aim of this study was to discover whether attitude and subjective norms could predict the intention to quit smoking among emerging adult women. Emerging adult is the stage of development where the prevalence of various substance abuses highest. We hypothesized that attitude and subjective norms would predict the intention to quit smoking among emerging adult women. Study was conducted on 211 emerging adult women those aged 18-25 years. Participants completed the questionnaire which composed by researcher using Theory of Planned Behavior approach and behavioral intention theory. Data were analyzed with multiple regression techniques. Results showed that attitudes $(B=0.229, S E=0.07, p$ value $=.003)$ and subjective norm ( $B=0.645, S E=.078, p$ value $=.000)$ positively correlate to intention to quit smoking among emerging adult women $\left(F\left(211=33.36, d f=207, R^{2}=.325, p\right.\right.$ value $\left.=.000\right)$. Results showed that the predictor accounted for $32.5 \%$ of variance of the dependent variable.
\end{abstract}

Keywords: intention to quit smoking, emerging adult woman, theory of planned behavior 
INSAN Jurnal Psikologi dan Kesehatan Mental, 2017, Vol. 2(2), 111-119, doi: 10.20473/jpkm.v2i22017.111-119 Dikirimkan: 30 Oktober 2017 Diterima: 13 Juli 2018 Diterbitkan: 19 Juli 2018

Editor: Dewi Syarifah

*Alamat korespondensi: Kampus B Universitas Airlangga, Jalan Airlangga 4-6 Surabaya, Jawa Timur 60286. Pos-el:vvaniakoe@gmail.com

Naskah ini merupakan naskah dengan akses terbuka dibawah ketentuan the Creative Common Attribution License (http://creativecommons.org/licenses/by/4.0), sehingga penggunaan, distribusi, reproduksi dalam media apapun atas artikel ini tidak dibatasi, selama sumber aslinya disitir dengan baik.

\section{PEN D A H U L U A N}

Dewasa ini, sering kita jumpai wanita merokok ditempat umum (Brahmana, 2009). Dari jumlah 1 miliar perokok aktif diseluruh dunia, 20\% diantaranya adalah wanita (Pusat Promosi Kesehatan, 2013), bahkan data menunjukkan bahwa jumlah perokok wanita meningkat setiap tahunnya (Lubis, 1994). Hasil Riset Kesehatan Dasar menunjukkan bahwa jumlah perokok wanita yang berusia diatas 15 tahun meningkat dalam rentang tahun 2007-2013, yaitu pada tahun 2007 jumlah perokok perempuan sebanyak 5.2\% dan pada tahun 2013 meningkat menjadi 6.7\% (Pusat Data dan Informasi Kementerian Kesehatan RI, 2015). Secara spesifik, sebanyak 2.1\% wanita yang berusia wanita diatas 15 tahun menghisap rokok (Badan Penelitian dan Pengembangan Kesehatan, 2013). Global Adult Tobacco Survey (GATS) juga menyebutkan bahwa dari 61 juta masyarakat Indonesia yang mengonsumsi tembakau baik dalam bentuk rokok atau smokeless, 4,5\% diantaranya wanita dewasa, namun diperkirakan persentase tersebut akan meningkat (World Health Organization, 2011).

Perilaku merokok pada wanita bisa terjadi pada setiap tahap perkembangan, namun menurut Arnett (2005), tahap emerging adult (18-25 tahun) merupakan tahap dimana prevalensi penyalahgunaan berbagai macam zat paling tinggi. Menurut Arnett (2000), masa emerging adult merupakan masa dimana individu memiliki berbagai macam pilihan terutama mengenai permasalahan cinta, pekerjaan, dan perspektif terhadap dunia. Individu emerging adult perlu mengembangkan sikap-sikap baru, berikut dengan nilai-nilai yang dianut. Berbeda dari remaja, emerging adult dianggap sebagai tahap dimana individu mulai mengeksplorasi diri dengan mencoba hal-hal baru dihidupnya yang bertujuan untuk mengetahui apa yang diinginkan dalam hidupnya (Arnett, 2004). Tanggung jawab yang harus dipenuhi tersebut dapat memicu munculnya berbagai konflik, ambiguitas, dan berbagai peran ganda yang cenderung sulit untuk diatur (White \& Jackson, 2005; Hildingh, Baigi, \& Lidell, 2006). Tugas-tugas emerging adult harus dipenuhi individu guna mencapai transisi yang berhasil menuju tahap perkembangan dewasa, sehingga hal tersebut dapat memberikan tekanan dan stres yang mengarahkan individu untuk melakukan perilaku yang tidak sehat (White \& Jackson, 2005).

Rokok memiliki banyak dampak negatif terhadap manusia, karena didalamnya terdapat banyak zat kimia yang membahayakan, maka bukan hal yang aneh apabila banyak dampak negatif yang muncul akibat rokok (Brahmana, 2009). Terdapat dampak perilaku merokok yang hanya berisiko muncul pada wanita, seperti risiko terkena kanker payudara, pendarahan pada saat menstruasi yang lebih deras, dan sering berubahnya siklus menstruasi (Perkins, 2001). Selain itu, wanita yang merokok cenderung mengalami kesulitan untuk hamil, serta mencapai menopause lebih dini yaitu satu hingga dua tahun lebih mudah daripada wanita seusianya yang tidak merokok, serta kulit cepat berkerut dan rambut cepat beruban (Lubis, 1994). Dampak-dampak lainnya yang hanya berisiko muncul pada perempuan adalah kelahiran prematur, aborsi spontan, dan kanker leher rahim (Brahmana, 2009). Perkins (2001) menjelaskan bahwa wanita perokok cenderung lebih berisiko terkena penyakit jantung dan kanker

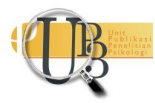


kandung kemih. Dijelaskan lebih lanjut, bahwa terdapat peningkatan terhadap risiko kanker paru-paru kronis, stroke, dan pnuemonia. Data lain juga menunjukkan bahwa wanita yang merokok dapat mengalami penundaan atau penurunan kemampuan untuk hamil (Kementerian Kesehatan Republik Indonesia, 2011).

Dengan memperhatikan dampak yang disebabkan oleh merokok, maka cepat atau lambat perilaku merokok harus dapat dihentikan (Ardini \& Hendriani, 2012). Banyak hal yang sudah dilakukan berbagai pihak untuk menurunkan angka perokok di Indonesia, seperti peraturan yang ditetapkan oleh pemerintah mengenai pengamanan rokok bagi kesehatan pada Peraturan Pemerintah RI Nomor 19 tahun 2003 dan promosi kesehatan yang berhasil masuk rekor MURI dengan mengumpulkan sekitar 700 ribu dukungan cap tangan anti rokok dari masyarakat dari berbagai daerah Indonesia. Selain itu, usaha lain juga dilakukan oleh masyarakat, seperti kampanye yang dilakukan oleh komunitas Wanita Indonesia Tanpa Tembakau (WITT) dengan mengajak masyarakat untuk menggalang tanda tangan anti merokok ("Para Wanita Surabaya," 2015), kemudian melalui media iklan baik di televisi, radio, ataupun surat kabar (Pusat Promosi Kesehatan, 2014). Sayangnya, usaha untuk menghentikan perilaku merokok bukan hal yang mudah untuk dilakukan terutama di Indonesia (Lubis, 1994; Ardini \& Hendriani, 2012).

Usaha yang dilakukan guna mengurangi angka perokok bukan hal yang mudah untuk dilakukan, hal ini ditunjukkan dengan jumlah perokok wanita di Indonesia yang masih tinggi bahkan cenderung meningkat tiap tahun (Maharani, 2015). Menurut McKee (2015) wanita cenderung sulit untuk berhenti merokok daripada laki-laki meskipun keuntungan untuk berhenti merokok lebih banyak dirasakan pada wanita daripada pada laki-laki (Dallas, 2015). Wetter, dkk. (1999) juga memaparkan bahwa perempuan lebih mungkin untuk berhasil berhenti merokok daripada laki-laki, namun perempuan akan lebih mudah untuk kambuh tepat setelah berhenti merokok. Wanita mengalami kesulitan berhenti merokok salah satunya karena tekanan dari lingkungan sosialnya (Nieva, dkk., 2011). Wanita juga cenderung merasa berat badannya naik ketika mencoba untuk berhenti merokok (Williamson, dkk., 1991). Sebagai tambahan, perokok wanita cenderung memiliki pasangan yang juga merokok (Homish \& Leonard, 2005; Manchon Walsh dkk., 2007 dalam Dohnke, dkk., 2011), sehingga hal ini cenderung menghalangi keinginan wanita untuk berhenti merokok (Bjornson, dkk., 1995; Homish \& Leonard, 2005; Manchon Walsh dkk., 2007 dalam Dohnke, dkk., 2011). Salah satu cara yang dapat digunakan untuk mengetahui kecenderungan seseorang untuk berhenti merokok adalah dengan cara mengukur intensinya untuk berhenti merokok. Intensi merupakan prediktor yang paling baik untuk memprediksi perilaku seseorang, karena intensi merepresentasikan kesiapan seseorang untuk melakukan perilaku tertentu dan juga dapat dianggap sebagai anteseden munculnya perilaku tersebut (Caulfield, 2007).

Dalam kajian psikologi kesehatan, terdapat salah satu konsep yaitu Theory of Planned Behavior yang merupakan konsep dengan tujuan untuk memprediksi perilaku manusia berdasarkan intensinya (Ajzen, 1991). Intensi terbentuk atas tiga prediktor, yaitu sikap terhadap tingkah laku, norma subjektif, dan perceived behavioral control (Ajzen, 1988). Banyak penelitian yang mengatakan bahwa TPB mampu memprediksi perilaku, seperti penelitian terdahulu mengenai intensi mengonsumsi alkohol (Schlegel, dkk, 1992), intensi penggunaan kondom (Boldero, dkk., 1992; Wilson, dkk., 1992), dan intensi pemeriksaan payudara atau testikel sejak dini (Young, dkk., 1991; McCaul, dkk., 1993). Namun penelitian mengenai TPB yang dikaitkan dengan perilaku berhenti merokok masih belum banyak (Norman, Conner, \& Bell, 1999). Terlebih lagi, berdasarkan penelitian Amos (1996), menunjukkan bahwa di negara berkembang wanita cenderung lebih sulit untuk berhenti merokok daripada laki-laki. Maka, penelitian mengenai intensi berhenti merokok akan lebih menarik jika dikaitkan dengan konteks gender. Hipotesis dari penelitian ini adalah prediktor dari variabel TPB (sikap dan norma subjektif) dapat digunakan untuk memprediksi intensi berhenti merokok pada wanita emerging adult. 


\section{MET ODE}

\section{Desain Penelitian}

Penelitian ini adalah penelitian kuantitatif dengan desain penelitian survei. Penelitian dilakukan pada rentang waktu kurang lebih 2 bulan dengan menggunakan Google form yang disebar secara online oleh peneliti. Pengambilan data juga dilakukan secara manual dengan membagikan kuesioner ke tempattempat tertentu seperti café atau restoran. Sebelum memutuskan untuk berpartisipasi, partisipan diminta untuk mengisi informed consent yang tertera pada instruksi dibagian awal kuesioner/ form

\section{Partisipan Penelitian}

Partisipan secara keseluruhan dalam penelitian adalah wanita emerging adult, yaitu mereka yang berumur 18-25 tahun menurut Arnett (2005). Pengambilan sampel pada penelitian ini menggunakan purposive sampling, dimana teknik ini dilakukan pada populasi khusus yang memiliki karakteristik dan ciri tertentu sesuai penelitian (Neuman, 2007).

Jumlah sampel dalam penelitian adalah 211 partisipan. Usia sampel yang paling banyak berada dalam rentang 21-22 tahun, dengan total persentase 52.1\% dari keseluruhan partisipan. Mayoritas partisipan penelitian adalah mahasiswa (74.88\%) dengan rentang usia yang telah dibatasi yaitu 18-25 tahun. Berdasarkan domisili yang telah dikategorikan menurut provinsi, mayoritas partisipan berasal dari provinsi Jawa Timur (63.51\%) dari total partisipan. Dalam kategori penggunaan rokok, didapatkan bahwa 50.24\% dari total keseluruhan partisipan berada dalam kategori perokok ringan, 38.86\% dalam kategori perokok sedang, dan sisanya dalam kategori berat.

\section{Pengukuran}

Skala yang digunakan dalam penelitian ini disusun sendiri oleh peneliti menggunakan pendekatan TPB pada perokok yang disusun berdasarkan dimensi TPB dari Ajzen (1991) dan skala intensi berhenti merokok yang disusun berdasarkan teori intensi perilaku dari Warshaw \& Davis (1985). Koefisien reliabilitas Cronbach's alpha skala TPB pada perokok adalah 0.826 pada sikap terhadap perilaku berhenti merokok, 0.751 pada norma partisipatif, dan 0.787 pada perceived behavioral control. Sementara pada skala intensi berhenti merokok didapatkan nilai reliabilitas sebesar 0.878.

\section{Analisis Data}

Analisis data dilakukan menggunakan teknik regresi linear berganda dengan bantuan program SPSS 20.0 for Macintosh. Analisis korelasi berganda dieksekusi setelah dilakukan uji asumsi yang terdiri dari uji normalitas dan uji multikolinearitas.

\section{HAS I L P E N EL I T IAN}

Sebelum analisis regresi dilakukan, uji korelasi terlebih dahulu dilakukan untuk mengetahui hubungan antara variabel-variabel TPB terhadap intensi berhenti merokok. Berdasarkan hasil uji korelasi, ditemukan bahwa dari tiga variabel TPB, sikap $(r=.284$, nilai $\mathrm{p}=.000, \mathrm{VIF}=2.133$, skewness $=0.388)$ dan norma subjektif $(r=.539$, nilai $\mathrm{p}=.000, \mathrm{VIF}=1.080$, skewness $=-0.433)$ ditemukan memiliki hubungan yang sedang dan positif dengan intensi berhenti merokok, sedangkan PCB $(r=.091$, nilai $\mathrm{p}=.187$, VIF $=2.040$, skewness $=0.424$ ) tidak berhubungan dengan intensi berhenti merokok. 
Analisis selanjutnya yang dilakukan adalah analisis regresi guna menjawab pertanyaan penelitian. Model regresi menunjukkan good fit $\left(\mathrm{F}(211)=33.36, \mathrm{df}=207, \mathrm{R}^{2}=.325\right.$, nilai $\left.\mathrm{p}=.000\right)$, dimana varians skor seluruh prediktor dapat menjelaskan varians skor variabel dependen sebesar 32.5\%. Diantara prediktor dalam Theory of Planned Behavior yang terdiri dari sikap terhadap perilaku, norma subjektif, dan PCB, terdapat dua prediktor yang mampu memprediksi intensi berhenti merokok pada wanita emerging adult, yaitu sikap terhadap perilaku berhenti merokok $(B=0.229, S E=0.07$, nilai $\mathrm{p}=.003)$ dan norma subjektif $(B=0.645, S E=.078$, nilai $\mathrm{p}=.000)$, sedangkan PCB $(B=-0.096, S E=.080$, nilai $\mathrm{p}=.232)$ bukan prediktor yang substantif bagi intensi berhenti merokok.

\section{I S K U S I}

TPB merupakan teori kesehatan yang digunakan untuk memprediksi perilaku berdasarkan intensinya (Ajzen, 1991). Menurut Ajzen (1991), intensi dianggap sebagai faktor motivasional bagi seseorang untuk melakukan sebuah perilaku, yaitu mengindikasikan seberapa keras usaha seseorang untuk merencanakan dan melakukan suatu perilaku tertentu. TPB dianggap sebagai salah satu konsep yang paling terkenal dan berpengaruh terhadap studi mengenai perilaku manusia (Ajzen, 2001 dalam Ajzen, 2002). TPB merupakan perluasan dari teori intensi Theory of Reasoned Action (TRA), dimana pada TRA teorinya membatasi pada perilaku yang berada di bawah kehendak orang yang bersangkutan (volitional behavior), sehingga TPB dikembangkan dengan menyertakan perilaku yang tidak sepenuhnya berada dalam kontrol kehendak (non-volitional behavior) (Conner \& Norman, 2003). TPB sendiri terdiri dari tiga prediktor yaitu sikap terhadap perilaku (attitude toward behavior), norma subjektif (subjective norms), dan PCB.

Hasil analisis dari sikap terhadap perilaku berhenti merokok dalam penelitian ini menunjukkan bahwa prediktor ini dapat memprediksikan intensi berhenti merokok pada wanita emerging adult. Hal ini sesuai dengan penelitian yang dilakukan oleh Moan dan Rise (2005) yang menunjukkan bahwa determinan sikap terhadap perilaku mampu memprediksi intensi mahasiswa untuk berhenti merokok. Hasil penelitian tersebut memaparkan bahwa sikap mahasiswa terhadap perilaku berhenti merokok berkontribusi paling besar terhadap intensi mereka untuk berhenti merokok daripada prediktor TPB lainnya. Selain itu, penelitian yang dilakukan oleh Rise, dkk. (2008) dengan memprediksi intensi berhenti merokok dan perilaku berhenti merokok menggunakan TPB juga menunjukkan bahwa sikap terhadap perilaku berhenti merokok memberikan kontribusi besar untuk mengukur intensi. Prediktor ini signifikan pada wanita emerging adult karena sejalan dengan salah satu karakteristik pada tahap perkembangan ini dimana individu emerging adult optimis dan terbuka pada semua kemungkinan, sehingga terkadang optimis yang mereka punya bias dan menyikapi hal-hal baru seperti merokok menjadi hal yang tidak memiliki konsekuensi negatif (Arnett, 2005; White \& Jackson, 2005).

Norma subjektif dalam penelitian ini juga mampu memprediksikan intensi berhenti merokok pada wanita emerging adult. Hal ini sejalan dengan penelitian yang dilakukan oleh Rise, dkk. (2008) dimana norma subjektif mampu memprediksikan intensi mahasiswa berhenti merokok. Dalam penelitian ini norma subjektif dibagi menjadi dua komponen yaitu norma deskriptif dan norma pengganti, dimana norma deskriptif merupakan persepsi individu atas apa yang orang lain lakukan dan norma pengganti yang merupakan persepsi individu atas apa yang orang lain harapkan untuk ia lakukan. Hasil penelitian secara spesifik menunjukkan bahwa norma deskriptif lebih memberikan kontribusi terhadap prediksi intensi berhenti merokok. Norma subjektif dianggap penting dan rentan bagi emerging adult karena pada umumnya individu baru memasuki lingkungan kampus yang baru atau tempat kerja baru, sehingga pengaruh lingkungan penting bagi mereka agar dapar beradaptasi dan mendapatkan teman baru (White \& Jackson, 2005). 
PCB dianggap kurang mampu memprediksi intensi berhenti merokok pada wanita emerging adult. Hal ini sesuai dengan penelitian yang dilakukan oleh Falomir dan Invernizzi (1999) dimana prediktor PCB kurang berperan secara signifikan dalam memprediksi intensi berhenti merokok pada siswa yang berada di bangku sekolah menengah atas di Spanyol. Menurut penelitian tersebut, kurangnya kontribusi PBC dikarenakan prediktor PBC lebih memprediksikan perilaku merokok daripada intensi berhenti merokok, selain itu kurangnya dampak dari PBC juga dikarenakan intensi tidak memediasi hubungan antara persepsi kontrol dan perilaku berhenti merokok. Sementara PBC merupakan prediktor yang bertujuan untuk memprediksi perilaku yang tidak sepenuhnya berada dalam kontrol sehingga bertentangan dengan karakteristik partisipan, maka dari itu hasil penelitian menunjukkan rendahnya signifikansi PBC. Selain itu, Glassman, dkk. (2010) juga menduga rendahnya peranan PBC dikarenakan kurangnya efektivitas aitem pada konstruk PBC, sehingga skala PBC perlu disusun kembali agar dapat menggambarkan PBC lebih efektif.

Hasil dari penelitian ini bertentangan dengan penelitian yang dilakukan oleh oleh Norman, dkk. (1999) yang mengaitkan TPB dengan intensi berhenti merokok pada 84 partisipan dengan usia berjenjang 16 hingga 69 tahun. Hasil penelitian yang dilakukan secara longitudinal tersebut menunjukkan bahwa kontribusi PBC paling dominan diantara prediktor lainnya. Selain itu, penelitian yang dilakukan Hu dan Lanese (1998) juga menunjukkan bahwa PBC memberikan kontribusi yang paling besar diantara prediktor TPB lainnya untuk memprediksi intensi berhenti merokok pada pekerja yang tersebar di tiga perusahaan di Taiwan.

Prediktor PBC merupakan perluasan dari TRA yang bertujuan untuk memprediksi perilaku yang tidak sepenuhnya berada dalam kontrol kehendak (non-volitional behavior) dan perannya dianggap penting dalam konsep TPB (Ajzen, 1991), namun peranannya untuk memprediksi suatu perilaku terkadang mengecewakan (Albarracin, dkk., 2001). Perbedaan signifikansi pada prediktor TPB dengan intensi berhenti merokok pada wanita emerging adult muncul dikarenakan tiap prediktor memberikan kontribusi secara independen. Variasi perilaku, situasi, dan target populasi yang diteliti menggunakan prediktor TPB juga mempengaruhi besar peranan tiap prediktor sehingga hasilnya bisa berbeda-beda di tiap penelitian (Ajzen, 1991; Shi, dkk., 2014).

Berdasarkan hasil penelitian diperoleh gambaran bahwa mayoritas wanita emerging adult yang merupakan perokok aktif menampilkan sikap terhadap perilaku berhenti merokok sangat rendah, begitu juga dengan norma subjektif yang mayoritas sedang, dan tingkat PCB partisipan yang berimbang pada kategori rendah dan sangat rendah. Dengan demikian untuk kategori intensi berhenti merokok partisipan cenderung memiliki tingkat intensi sangat rendah.

\section{S I M P U L A N}

Berdasarkan hasil analisis data dan pembahasan penelitian, maka dapat disimpulkan bahwa TPB dapat digunakan sebagai prediktor intensi berhenti merokok pada wanita emerging adult. Hasil penelitian menunjukkan bahwa prediktor sikap terhadap perilaku berhenti merokok dan norma subjektif yang diketahui mampu memprediksi intensi berhenti merokok pada wanita emerging adult. Saran untuk penelitian selanjutnya adalah memperbaiki alat ukur TPB dan intensi berhenti merokok dengan melakukan uji coba terlebih dahulu agar mampu mengukur konstruk lebih baik. Selain itu, penelitian selanjutnya dapat memiliki metode penelitian yang lebih baik agar hasil penelitian mampu digeneralisasikan secara luas, seperti melakukan pemilihan partisipan dengan jumlah populasi yang diketahui sehingga jumlah sampel ideal untuk dilakukan generalisasi. Peneliti selanjutnya juga dapat memberikan kontrol terhadap variabel lain yang berpotensi untuk mempengaruhi prediktor dan intensi berhenti merokok. Saran bagi wanita emerging adult yang masih aktif merokok diharapkan mencari informasi mengenai dampak-dampak merokok khususnya bagi wanita. Penelitian mengenai TPB pada

INSAN Jurnal Psikologi dan Kesehatan Mental

2017, Vol. 2(2), 111-119

doi: 10.20473/jpkm.v2i22017.111-119

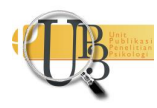


wanita emerging adult yang perokok dapat dijadikan masukan bagi mereka yang ingin berhenti merokok.

\section{P US T A KA A C UAN}

Ajzen, I. (1988). Attitudes, Personality, and Behavior. England: Open University Press.

Ajzen, I. (1991). The theory of planned behavior. Organizational Behavior and Human Decision Processes, $50,179-211$.

Ajzen, I. (2002). Perceived Behavioral Control, Self-Efficacy, Locus of Control, and the Theory of Planned Behavior. Journal of Applied Social Psychology, 32, 665-683.

Albarracin, D., Johnson, B. T., Fishbein, M., \& Muellerleile, P. A. (2001). Theories of Reasoned Action and Planned Behavior as Models of Condom Use: A Meta-Analysis. Psychological Bulletin, 127(1), 142161.

Amos, A. (1996). Women and Smoking. British Medical Bulletin, 52(1), 74-89.

Ardini, R. F. \& Hendriani, W. (2012). Proses Berhenti Merokok Secara Mandiri Pada Mantan Pecandu Rokok Dalam Usia Dewasa Awal. Jurnal Psikologi Pendidikan dan Perkembangan, 1(2).

Arnett, J. J. (2000). Emerging adulthood: A theory of development from the late teens through the twenties. American Psychologist, 55(5), 469.

Arnett, J. J. (2004). Emerging Adulthood: The Winding Road from the Late Teens Through the Twenties. New York: Oxford University Press.

Arnett, J. J. (2005). The developmental context of substance use in emerging adulthood. Journal of Drug Issues, 35(2), 235-254.

Badan Penelitian dan Pengembangan Kesehatan. (2013). Hasil riset kesehatan dasar (Riskesdas) 2013. Badan Penelitian dan Pengembangan Kesehatan Menteri Kesehatan RI 2013.

Bjornson, W., Rand, C., Connett, J. E., Lindgren, P., Nides, M., Pope, F., Buist, S., Hoppe-Ryan, C., \& O'Hara, P. (1995). Gender differences in smoking cessation after 3 years in the Lung Health Study. American Journal of Public Health, 85, 223-230.

Boldero, J., Moore, S., \& Rosenthal, D. (1992). Intention, context, and safe sex: Australian adolescents' responses to AIDS. Journal of Applied Social Psychology, 22, 1374-96.

Brahmana, K. M. (2009). Gambaran Faktor-Faktor yang Mempengaruhi Wanita Dewasa Muda dalam Mengambil Keputusan Mengkonsumsi Rokok (Jenis Lights atau Non-Lights). VISI, 17 (1), 90-107.

Caulfield, B. (2007). The Theory of Planned Behaviour. Trinity College Dublin [on-line]. Diakses pada 7 Juni 2015 dari http://www.tcd.ie/civileng/Staff/Brian.Caulfield/T2\%20\%20Transport\%20Modelling/The\%20Theory\%20of\%20Planned\%20Behaviour.pdf

Conner, M. \& Norman, P. (2003). Predicting Health Behavior (2 ${ }^{\text {nd }}$ Ed.). UK: Open University Press.

Dallas, M. E. (2015, 13 Oktober). Anti-Smoking Drug May Help Women Sooner Than Men. WebMD [online]. Diakses pada 17 November 2015 dari http://www.webmd.com/smokingcessation/news/20151013/anti-smoking-drug-chantix-may-help-women-sooner-than-men

Dohnke, B., Weiss-Gerlach, E., \& Spies, C. D. (2011). Social Influences on the Motivation to Quit Smoking: Main and Moderating Effects of Social Norms. Addictive Behaviors, 36, 286-293.

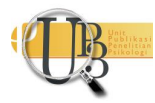


Falomir, J. M., \& Invernizzi, F. (1999). The role of social influence and smoker identity in resistance to smoking cessation. Swiss Journal of Psychology, 58(2), 73-84.

Glassman, T., Braun, R. E., Dodd, V., Miller, J. M., \& Miller, E. M. (2010). Using the Theory of Planned Behavior to Explain the Drinking Motivations of Social, High-Risk, and Extreme Drinkers on Game Day. Journal Community Health, 35, 172-181.

Hildingh, C., Baigi, A., \& Lidell, E. (2006). Stress and self-rated health; comparison between 26-year old Swedish women at intervals of twenty. Nordic Journal of Nursing Research \& Clinical Studies/Vård i Norden, 26(3).

Homish, G. G. \& Leonard, K. E. (2005). Spousal influence on smoking behaviors in a US community sample of newly married couples. Social Science \& Medicine, 61, 2557-2567.

Hu, S-C., \& Lanese, R. R. (1998). The applicability of the theory of planned behavior to the intention to quit smoking across workplaces in Southern Taiwan. Addictive Behaviors, 23(2), 225-237.

Kementerian Kesehatan Republik Indonesia. (2011). Pedoman Pengembangan Kawasan Tanpa Rokok. Jakarta: Pusat Promosi Kesehatan.

Lubis, A. (1994). Wanita dan Rokok. Media Litbangkes, 4(4), 12-15.

Maharani, D. (2015, 29 Mei). Jumlah Perokok Wanita di Indonesia Meningkat Tajam. Tribun News [online]. $\quad$ Diakses $\quad$ pada $15 \quad 15015$ Juni http://www.tribunnews.com/kesehatan/2015/05/29/jumlah-perokok-wanita-di-indonesiameningkat-tajam

McCaul, K. D., Sandgren, A. K., O’Neill, H. K., \& Hinsz, V. B. (1993). The value of the theory of planned behavior, perceived control, and self-efficacy expectations for predicting health-protective behaviors. Basic and Applied Social Psychology, 14, 231-52.

McKee, S. A., Smith, P. H., Kaufman, M., Mazure, C. M., \& Weinberger, A. H. (2016). Sex Differences in Varenicline Efficacy for Smoking Cessation: A Meta-Analysis. Nicotine \& Tobacco Research, 18(5), 1002-1011.

Moan, I. S. \& Rise, J. (2005). Quitting Smoking: Applying an Extended Version of the Theory of Planned Behavior to Predict Intention and Behavior. Journal of Applied Biobehavioral Research, 10(1), 3968.

Neuman, W. L. (2007). Basic of Social Research: Qualitative and Quantitative Approaches (2nd Edition). Boston: Pearson Education.

Nieva, G., Valero, S., Bruguera, E., Andion, A., Trasovres, M. V., Gual, A., \& Casas, M. (2011). The Alternative Five Factor Model of Personality, Nicotine Dependence and Relapse Past Treatment for Smoking Cessation. Addictive Behaviors, 36(10), 965-971.

Norman, P., Conner, M., \& Bell, R. (1999). The theory of planned behavior and smoking cessation. Health Psychology, 18(1), 89-94.

Para Wanita Surabaya Galang Tanda Tangan Antitembakau. (2015, 31 Mei). Berita Satu [on-line]. Diakses pada 26 Juli 2015 dari http://www.beritasatu.com/kesehatan/278634-para-wanitasurabaya-galang-tanda-tangan-antitembakau.html

Perkins, K. A. (2001). Smoking Cessation in Women: Special Considerations. CNS Drugs, 15(5), 391-411.

Pusat Data dan Informasi Kementerian Kesehatan RI (2015, Mei). Perilaku merokok masyarakat Indonesia: Berdasarkan Riskesdas 2007 dan 2013. Diakses pada 29 Mei 2016 dari 
http://www.depkes.go.id/resources/download/pusdatin/infodatin/infodatin-hari-tanpatembakau-sedunia.pdf

Pusat Promosi Kesehatan (2014, 14 Oktober). Peluncuran ILM kampanye anti rokok: Berhenti menikmati rokok sebelum rokok menikmatimu. Pusat Promosi Kesehatan [on-line]. Diakses pada 31 Mei 2015 dari http://promkes.depkes.go.id/peluncuran-ilm-kampanye-antirokok-berhentimenikmati-rokok-sebelum-rokok-menikmatimu/

Rise, J., Kovac, V., Kraft, P., \& Moan, I. S. (2008). Predicting the intention to quit smoking and quitting behaviour: Extending the theory of planned behavior. British Journal of Health Psychology, 13, 291310.

Schlegel, R. P., D’ Avernas, J. R., Zanna, M. P., \& DeCourville, N. H. (1992). Problem drinking: A problem for the theory of reasoned action? Journal of Applied Social Psychology, 22, 358-85.

Shi, Y., Ehlers, S., \& Warner, D. O. (2014). The Theory of Planned Behavior as Applied to Preoperative Smoking Abstinence. Anesthesiology, 9(7), 1-6.

Warshaw, P. R. \& Davis, F. D. (1985). Disentangling Behavioral Expectation and Behavioral Expectation. Journal of Experimental Social Psychology, 21, 213-228.

Wetter, D. W., Kenford, S. L., Smith, S. S., Fiore, M. C., Jorenby, D. E., \& Baker, T. B. (1999). Gender Differences in Smoking Cessation. Journal of Consulting and Clinical Psychology, 67(4), 555-562.

White, H. R. \& Jackson, K. (2005). Social and Psychological Influences on Emerging Adult Drinking Behavior. Alcohol Research \& Health, 28(4), 182-190.

Williamson, D. F., Madans, J., Anda, R. F., Kleinman, J. C., Giovino, G. A., \& Byers, T. (1991). Smoking Cessation and Severity of Weight Gain in a National Cohort. The New England Journal of Medicine, 324(11), 739-745.

Wilson, T. D., Zenda, A., McMaster, J., \& Lavelle, S. (1992). Factors predicting Zimbabwean students' intentions to use condoms. Psychology and Health, 7, 99-114.

World Health Organization. (2011). Global Adult Tobacco Survey: Indonesia Report 2011. Diakses dari http://www.who.int/tobacco/surveillance/survey/gats/indonesia_report.pdf

Young, H. M., Lierman, L., Powell-Cope, G., \& Kasprzyk, D. (1991). Operationalizing the theory of planned behavior. Research in Nursing and Health, 14, 137-44. 